\title{
Cyclic flexural resistance of newly introduced NiTi rotary file system: An in-vitro study
}

\author{
Akanksha Bhatt ${ }^{1, *}$ B. Rajkumar', Vishesh Gupta ${ }^{3}$ \\ ${ }^{\mathbf{1}}$ Reader, ${ }^{2}$ Principal and HOD, ${ }^{3}$ Reader, Dept. of Conservative Dentistry \& Endodontics, Babu Banarasi Das College of Dental \\ Sciences, BBD University, Lucknow, India \\ *Corresponding Author: \\ Email: dr.a.bhatt@gmail.com
}

\begin{abstract}
This study aimed to compare the cyclic fatigue fracture resistance of different rotary NiTi file systems. Hero shaper rotary file, one shape rotary file and a new rotary file system profile vortex were tested. The cyclic fatigue testing was conducted using a simulated root canal apparatus with an angle of curvature $60^{\circ}$ and radius of curvature of $5 \mathrm{~mm}$. Total sample size of 30 rotary files (10 files in each experimental group) were selected for the study. The files were rotated at $400 \mathrm{rpm}$ using the triauto mini endomotor set at $2.5 \mathrm{~N} / \mathrm{cm}$ torque, until fracture occurred. The time until fracture was recorded in seconds by using a digital stopwatch, and the number of rotations till fracture was then calculated using a mathematical formula. The results were then statistically analysed. Profile vortex (Group 3) was found superior as compared to one shape (Group 2) and hero shaper (Group 1) endodontic rotary NiTi file system in cyclic fatigue testing.
\end{abstract}

Keywords: Cyclic fatigue, Flexural fatigue resistance, Static flexural fracture resistance.

\section{Introduction}

Root canal preparation is a great challenge especially in a curved root. Rotary Ni-Ti files are helpful to prepare curved root canals keeping the failure rate at low due to their more elasticity modulus and better flexible in bending \& torsion as compared with similar size stainless steel files. ${ }^{1}$

Despite the advantages of rotary Ni-Ti instruments, still a major concern exists about its fracture within the root canal while in use. ${ }^{2-4}$ Fracture occurs without any warning and without any visible defects of previous permanent deformation. Mainly two modes of fracture of rotary $\mathrm{Ni}-\mathrm{Ti}$ endodontic instruments have been identified: Torsional fracture and flexural fracture. ${ }^{5}$ Among these, fracture due to fatigue resistance has been considered as an important factor when dealing with rotary endodontic file system. This in-vitro study evaluated and compared cyclic fracture resistance of different types of endodontic rotary NiTi files

\section{Methodology}

The experimental group endodontic rotary file system Group 1: Hero shaper (Micromega, France), Group 2: One shape (Micro Mega, Besancon, France) and Group 3: Profile vortex (Tulsa Dental, U.S.A.) were chosen. The tip size ISO $25,21 \mathrm{~mm}$ in length were kept as parameters for standardization.

A simulated testing apparatus was constructed and used that allowed fatigue test to be conducted in a manner similar to that used in Youssef et al. $^{8}$ The apparatus comprised of three cylindrical steel blocks (one supporting block and two shaping block) attached on a $6 \mathrm{~mm}$ thick metal sheet. The positions of the shaping blocks was adjusted in order to get the desired degree of curvature $\left(60^{\circ}\right)$ which mimicked root canal curvature. Ten samples of each experimental groups were tested. The instruments were rotated at $400 \mathrm{rpm}$ at $2.5 \mathrm{~N} / \mathrm{cm}$ torque using the Tri auto mini endomotor. The following instrumentation protocol was followed by each experimental group file. First, the Ni-Ti file was coated with a layer of root canal lubricant EDTA gel. It was then placed in endomotor handpiece with its rubber stopper at the supporting steel cylinder and end between two shaping steel cylinders. The torque of $2.5 \mathrm{~N} / \mathrm{cm}$ and rpm of 400 was preset in endomotor handpiece. The file was then allowed to rotate and simultaneously the digital stopwatch was stared. The time (in seconds) till the fracture of experimental file occurred was recorded by using the stopwatch.

The number of rotations made by file till its fracture was than calculated using the formula:

No. of cycles till fracture $(\mathrm{NCF})=\frac{400}{60} \times$ Time taken

till fracture (in seconds).

Where 400 is revolution per minute (r.p.m)

\section{Results}

Observations were laid down regarding) the time taken (in seconds) till fracture of the file (Table 1). On this basis the number of rotations till file got fractured (Table 2) was calculated mathematically using the formula. Statistical analysis was then performed. 
Table 1: Time taken till fracture of experimental file

\begin{tabular}{|l|c|c|c|}
\hline $\begin{array}{l}\text { Sample } \\
\text { no. }\end{array}$ & $\begin{array}{c}\text { Time taken for Hero } \\
\text { Shapers file (Group 1) }\end{array}$ & $\begin{array}{c}\text { Time taken for One } \\
\text { Shape (Group 2) }\end{array}$ & $\begin{array}{c}\text { Time taken for Profile } \\
\text { Vortex file (Group 3) }\end{array}$ \\
\hline 1 & 12 & 40 & 14 \\
\hline 2 & 8 & 38 & 10 \\
\hline 3 & 10 & 32 & 12 \\
\hline 4 & 8 & 30 & 10 \\
\hline 5 & 12 & 34 & 14 \\
\hline 6 & 10 & 30 & 12 \\
\hline 7 & 10 & 34 & 14 \\
\hline 8 & 9 & 36 & 10 \\
\hline 9 & 8 & 38 & 12 \\
\hline 10 & 7 & 38 & \\
\hline
\end{tabular}

Table 2: Number of rotations till fracture

\begin{tabular}{|l|c|c|c|}
\hline Sample no. & Hero Shaper (Group 1) & One Shape (Group 2) & Profile Vortex (Group 3) \\
\hline 1 & 75 & 250 & 87.5 \\
\hline 2 & 50 & 237.5 & 62.5 \\
\hline 3 & 62.5 & 200 & 75 \\
\hline 4 & 50 & 187.5 & 62.5 \\
\hline 5 & 75 & 212.5 & 87.5 \\
\hline 6 & 62.5 & 181.5 & 75 \\
\hline 7 & 62.5 & 212.5 & 87.5 \\
\hline 8 & 56.25 & 225 & 62.5 \\
\hline 9 & 50 & 237.5 & 62.5 \\
\hline 10 & 43.75 & 237.5 & 75 \\
\hline
\end{tabular}

Time taken to fracture ranged from 7 to 40 seconds in groups tested. Mean time taken to fracture was minimum in Group I followed by Group III and Group II respectively. Mean number of cycles before fracture was minimum in Group I followed by Group III and Group Vrespectively. Analysis of variance showed a statistically significant intergroup difference $(p<0.001)$.

The results showed that the number of rotations until fracture for one shape (Group 1) was significantly greater than that of Profile Vortex (Group 2) and hero shaper (Group 3) tested.

\section{Discussion}

The present in-vitro study was conducted in Department of Conservative Dentistry \& Endodontics, at Babu Banarasi Das College of Dental Sciences, Babu Banarasi Das University, Lucknow, in collaboration with Department of Mechanical Engineering, Indian Institute of Technology, Kanpur, Uttar Pradesh, and IFFCO Amla, Bareilly, Uttar Pradesh, India.

The cyclic fracture resistance of three recent endodontic rotary NiTi files: Hero shapers (Micro Mega, Besancon, France), Profile Vortex (Dentsply Tulsa Dental Specialities, Tulsa, OK, U.S.A) and one shape (Micro Mega, Besancon Cedex, France) were evaluated. The inclusion criteria for choosing the above mentioned experimental rotary files was as follows: A recent introduced rotary file system manufactured from Conventional NiTialloy: One shape designated as Group 1 and a recent introduced rotary file system manufactured by M-Wire technology: Profile Vortex designated as Group 2 and hero shaper designated as Group 3.Exclusion criteriabeing Endodontic Stainless steel hand files, Endodontic NiTi hand files and Endodontic used files.

The present in-vitro study comprised of direct comparison of cyclic fatigue resistance among the NiTi rotary files being tested, therefore a separate control group was not required. To have uniformity in comparative study, all the rotary $\mathrm{NiTi}$ experimental files with ISO no.25, length $21 \mathrm{~mm}$ and taper 0.06 were kept standardized during the study. The constructed simulated root canal apparatus was inspired by design of apparatus constructed by Cheung GSP et al. ${ }^{9}$ The instrumentation protocol was followed for each experimental file group being tested for cyclic fracture resistance testing in accordance with the study conducted by Gupta $\mathrm{M}$ et al. ${ }^{10}$ To understand fracture resistance of a rotary NiTi file one has to know about the factors which influence the cyclic fracture resistance. As the reasons are complex therefore a proper understanding of the mechanisms for failure could provide insight for instrument design and the manufacturing process.

One shape file manufactured by Micro Mega Company, Besancon, France belongs to group of single file system. This instrument is made of aconventional austenite $55 \mathrm{NiTi}$ alloy. It has asymmetric triangular file geometry. In the tip region, thecross section represents three cutting edges while in themiddle of the 
cross-sectional design progressively changesfrom a three-cutting-edge design to two cutting edges. Atthe shank, the S-shaped cross section shows two cuttingedges, resembling the cross-sectional design of reciprocinstruments. This design is helpful in elimination of threadingand binding of the file in continuous rotation. This file is characterized bydifferent cross-sectional designs over the entire length ofthe working part and its design is alleged to guaranteemore flexibility.

The present in- vitro study results showed superior cyclic fatigue resistance for one shape file. This can be attributed due to its variable cross section with small residual core and electropolished surface of file as supported in the findings of study done by Dagna A et al. ${ }^{11}$ According to the manufacturer, the variable horizontal cross-section design of the file reducesthe effect of the file being screwed into canal walls. Also, the manufacturer claimed that byincreasing the pitch length between the variable horizontal cross-sections in one shape file, the flexibility of the file has improved leading to increase in file's resistance to cyclicfatigue. This finding has been also supported by the results obtained in the study by TahaOzyurek et al. ${ }^{12}$

In the present study, cyclic fracture resistance of profile vortex files was found good than its competitor hero shapers file system. Profile vortex file have a triangular cross section file design with no radial lands and has a variable helical angle design. It is manufactured from $\mathrm{M}$ wire technology. This new alloy (M-Wire) was composed of SE508nitinol that had undergone a proprietary method of treatmentcomprised of drawing the raw wire under specific tension and heattreatments at various temperatures, resulting in a material that includesportions in both the martensitic and the premartensitic R-phase while maintaining a pseudoelastic state. According to Shen $\mathrm{Y}$ et al. ${ }^{13,14}$ and Johnson E et al. ${ }^{15}$ and McKelvey AL et al. , ${ }^{16}$ various forms of the NiTi material (stable or superelastic austenite or stable martensite) have a similar ultimate strength but a different fatigue behaviour. The superelastic NiTi possesses the lowest fatigue-crack initiationthreshold and the worst crack propagation properties among the three forms, thebest being the stable martensitic structure. The findings of studies conducted by Johnson E et al. and Gao Y et al. (2010, 2012) found that Vortex instruments made from the MWire exhibitedsuperior cyclic fatigue resistance compared with those made of regular superelastic NiTi files. ${ }^{15,17,18}$

Gao Y et al. in 2010 showed that file made from M Wire has a single crack initiation site as compared to multiple crack initiation sites on files made of regular NiTi wire. ${ }^{17}$ Yong $\mathrm{G}$. et al also stated that $\mathrm{M}$ wire files showed increased resistance to fracture due to fatigue due to better re-orientation capability of Martensitic variants because of the lower symmetry of the monoclinic crystal structure of martensite than the cubic crystal structure of austenite. ${ }^{18}$ Together with the austenite-to-martensite phase transition mechanism, the favourable reorientation of localized martensite variants would provide a better accommodation of deformation during bending rotation fatigue and effectively reduce the time on formation and accumulation of microstructural defects such as surface irregularities or subsurface voids in which fatigue cracks could nucleate.

According to McKelvey et al. (2001), the fatigue crack growth resistance of the martensite was found to be superior to that of the stable austenite, particularly in the near threshold by comparing the fatigue behaviour of the various microstructures in Nitinol..$^{16}$ It was found by Bhatt et al. (2016), Bhatt et al. (2016), Dauskardt RH et al. (1989), Bhatt et al (2016), Bhatt et al (2017) and Gao Y et al. (2010) that at the same stress intensity level, the fatigue crack propogation speed of austenitic structure is much faster than martensite. ${ }^{16,17,20-23}$ This is generally explained by a small-volume contraction ($0.5 \%$ ) during austenite-to-martensite transformation that has a deleterious effect on the fatigue resistance by locally raising the stress intensity at the crack tip.

Gao Y et al. (2010) also showed that Vortex instruments made of M-Wire exhibited superior cyclic fatigue resistance (an approximately 150\% longer fatigue life) compared with those made of regular wire. ${ }^{17}$ The Vortex was superior even when the geometric design and the surface finish were kept identical. Therefore, the superior cyclic fatigue resistance was attributed to the microstructure resulting from the chemical composition and manufacturing techniques of NiTi alloy. Similar finding was shown by research performed by Alapati et al. and Plotino G et al. ${ }^{24,25}$

Kim JY et al. stated that profile vortex system is more resistance to cyclic fatigue. It was believed due to Enthalpy changes and different $A_{f}$ temperature. $A_{f}$ temperature was upto $50^{\circ} \mathrm{C}$ and Martensitic phase transformation condition existed at room temperature. ${ }^{26}$

Study performed by Gao Y et al. also demonstrated the results similar to the present study. ${ }^{18}$ They found that M-Wire manufactured files like Profile Vortex showed substantial growth of the martensite grains and marten site twins in the microstructureafter $60 \%$ of their fatigue life. This was due to its unique nano crystalline martensitic microstructure.

In the present study, the least cyclic fracture resistance or least survival time was shown by hero shapers file (Group I).

Hero shapers file system manufactured by micro mega company has a variable helical angle and adapted pitch. This means that the more tapered an instrument is, the longer is its pitch. It has a positive rake angle and the blade shows asymmetric triple helix file design. The tip is inactive in order to follow canal anatomy. An invitro study performed by Gupta $M$ et al. evaluated cyclic fatigue resistance of hero shaper rotary file in a 
curved canal. ${ }^{10}$ It has been found that hero shapers have a relatively narrow range of elasticity due to alteration in grain structure caused by grinding process. Moreover, grinding across the grain structure creates micro fracture points and defects along the length of the instrument. These defects causes stress concentration points that weaken the instruments and leads to fracture of instrument. They reported that cracks propagate at a stress level much lower than the stress usually encountered during canal instrumentation leading to sudden unexpected root canal file breakage.

A study conducted by Lee MH et al. evaluated cyclic fatigue of various NiTi files including hero shapers rotary file system using a custom made device and reported that hero shaper files showed lower cyclic fatigue resistance that its other competitors. ${ }^{27}$ This was attributed to the increased stress levels in file that accelerated the fatigue process.

The studies conducted by Cheung GSP et al. (2011) and Capar ID et al. (2015) determined that instruments with a triangular cross-sectional design possessed greater cyclic fatigue resistance than those with a square cross-sectional design. ${ }^{28,29}$ This difference is related to the reduced metal mass of the files with a triangular cross section compared with files with a square cross section and similar diameter.

\section{Conclusion}

The present study made a sincere attempt to meet its aim and objective to evaluate the fracture resistance of different types of endodontic rotary files manufactured from different recent manufacturing method. The maximum survival time and superior cyclic fracture resistance was shown by one shape file and least survival time was observed in hero shaper file.

\section{References}

1. Walia H, Brantley W A, Gerstein H. An initial investigation of the bending and torsional properties of nitinol root canal files. J Endod 1988;14:346-51.

2. Huismann M, Peters OA, Dummer PMH. Mechenical preparation of root canals: shaping goals, techniques and means. Endod Topics 2005;10:30-76.

3. Spili P, Parashos P, Messer HH. The impact of instrument fracture on outcome of endodontic treatment. J Endod 2005;31:845-50.

4. Souter NJ, Messer HH. Complications associated with fractured file removal using an ultrasonic technique. $\mathrm{J}$ Endod 2005;31:450-2.

5. Sattapan B, Nervo GJ, Palmara JEA, Messer HH. Defects in rotary nickel-titanium files after clinical use. J Endod 2000;26:161-5.

6. Margot E Anderson, John WH, Peter Parashos. Fracture resistance of electropolished rotary nickel titanium endodontic instruments. J Endod 2007;33:1212-16.

7. BrouchHyflexCM, The new generation of NiTi Files.

8. Youssef Haikel, Rene Serfaty, Geoff Bateman, Bernard Senger, ClaudAllemann. Dynamic and cyclic fatigue of engine driven rotary Nickel-Titanium endodontic instruments. J Endod 1999;25:434-440.

9. Cheung GSP and Darvell BW (2007). Fatigue testing of a NiTi rotary instrument. Part 2: Fractographic analysis.
International Endodontic Journal, Vol. 40, Issue 8, pp. 619-625.

10. Gupta M (2010) Gupta M, Mulay S (2010).Evaluation of cyclic fatigue resistance of three rotary nickel titanium endodontic instruments in curved canals - In vitro study. Endodontology, Vol. 22 Issue 2, pp.14-18.

11. Dagna A Dagna A, Poggio C, Beltrami R, Colombo M, Chiesa M, Bianchi S (2014). Cyclic fatigue resistance of OneShape, Reciproc, and Wave One: An in vitro comparative study. Journal of Conservative Dentistry, Vol.17, Issue 3,pp.250-254.

12. TahaOzyurek et al. Ozyurek T, Yilmaz K, Uslu G (2016). Comparison of cyclic fatigue resistance of old and new generation one shape NiTi instruments. International Journal of Applied Dental Sciences;2(4):04-07.

13. Shen Y et al. (2011) Shen Y, Zhou H-m, Zheng Y-f, Campbell L, Peng B, Haapasalo M (2011). Metallurgical Characterization of Controlled Memory Wire NickelTitanium Rotary Instruments. Journal of Endodontics 2011;37(11):1566-1571.

14. 14Shen Y et al. (2012) Shen Y, Qian W, Abtin H, Gao Y, Haapasalo M (2012). Effect of environment on fatigue failure of controlled memory wire nickel-titanium rotary instruments. Journal of Endodontics; 38(3):376-380.

15. Johnson E et al. (2008) Johnson E, Lloyd A, Kuttler S, Namerow K (2008). Comparasion between a novel nickel titanium alloy and 508 nitinol on the cyclic fatigue life of profile25/.04 rotary instruments. Journal of Endodontics 2008; 34, 11, pp1406-09.

16. Bhatt et al (2016) A comparative analysis of cyclic fatigue resistance of new rotary NiTi file systems (Hyflex CM and One Shape): An In-Vitro Study. Indian Journal of Basic and Applied Medical Research; December 2016: Vol.-6, Issue- 1, P. 183-187.

17. Gao Y et al. (2010) Gao Y, Shotton V, Wilkinson K, Phillips G, Johnson WB (2010). Effects of raw material and rotational speed on the cyclic fatigue of Profile Vortex rotary instruments. Journal of Endodontics, Vol. 36 Issue 7, pp. 1205-1209.

18. 18.Gao Y et al. (2012) Gao Y, Gutmann JL, Wilkinson K, Maxwell R, Ammon D.(2012). Evaluation of the Impact of Raw Materials on the Fatigue and Mechanical Properties of Profile Vortex Rotary Instruments. Journal of Endodontics, Vol. 38 Issue 3, 398-401.

19. Young G 2010 Young JM and Van Vliet KJ (2005). Predicting in vivo failure of pseudoelastic NiTi devices under low cycle, high amplitude fatigue. Journal of biomedical materials research. Part B, Applied biomaterials, Vol. 72, Issue 1, pp. 17-26.

20. Bhatt et al. (2016) evaluation of cyclic fatigue resistance of rotary niti vs controlled memory endodontic file systems: an in-vitro study. m edico research chronicles, 6,3,(3), 278-282.

21. Dauskardt RH et al. (1989) cyclic fatigue behaviour in ceramics. Closed loop, vol 17, no.2,7-17.

22. Bhatt et al (2016) Acomparative evaluation of cyclic fatigue resistance of two recent rotary NiTi endodontic file systems- An in-vitro study. Internatinal journal of clinical and public health research, 1(1):15-17.

23. Bhatt et al (2017) A comparative evaluation of flexural fatigue resistance of protaper next and profile vortex. An in-vitro study. Journal of biomedical and pharmaceutical research.6 (1) : 81-84.

24. Alapati et al. (2009) Alapati SB, Brantley WA, Iijima M, Schricker SR, Nusstein JM, Li UM, Svec TA (2009). Micro-XRD and temperature-modulated DSC investigation of nickel-titanium rotary endodontic 
instruments. Dental Materials, Vol. 25, Issue 10, pp.12211229.

25. Plotino G et al. (2014) Plotino G, Grande NM, Cotti E, Testarelli L, Gambarini G (2014). Blue treatment enhances cyclic fatigue resistance of vortex nickeltitanium rotary files. Journal of Endodontics; 40(9):14511453.

26. Kim JY et al. (2012) Kim JY, Cheung GS, Park SH, Ko DC, Kim JW, Kim HC (2012). Effect from cyclic fatigue of nickel-titanium rotary files on torsional resistance. $\mathbf{J}$ Endod. 38(4):527-30.

27. Lee MH et al. (2011) Lee MH, Versluis A, Kim BM, Lee CJ, Hur B, Kim HC (2011). Correlation between experimental cyclic fatigue resistance and numerical stress analysis for nickel-titanium rotary files. Journal of Endodontics. 37(8):1152-7.

28. Cheung GSP (2011) Cheung GSP, Zhang EW, Zheng YF (2011). A Numerical Method for Predicting the Bending Fatigue Life of NiTi and Stainless Steel Root Canal Instruments. International Endodontic Journal, Vol. 44, Issue 4, pp.357-361.

29. Capar ID et al. (2015) Capar ID, Kaval ME, Ertas H, Sen $\mathrm{BH}$ (2015). Comparison of the cyclic fatigue resistance of 5 different rotary path finding instruments made of conventional nickel-titanium wire, $\mathrm{M}$-wire, and controlled memory wire. Journal of Endodontics, Vol.41, Issue 4, pp.535-538. 